\title{
A Four-Parameter Extension of Burr III Distribution with Applications
}

\author{
Emmanuel W. Okereke ${ }^{1 *}$ and Johnson Ohakwe ${ }^{2}$ \\ ${ }^{1}$ Department of Statistics, Michael Okpara University of Agriculture, PMB, 7267, Umudike, Abia State, Nigeria \\ ${ }^{2}$ Department of Mathematics and Statistics, Faculty of Sciences, Federal of Sciences, Federal University, \\ Otuoke, PMB, 126, Yenogoa, Bayelsa State, Nigeria \\ Email:*okereke.emmanuel@mouau.edu.ng, ohakwejj@fuotuoke.edu.ng
}

\begin{abstract}
In this paper, we defined and studied a new distribution called the odd exponentiated half-logistic Burr III distribution. Properties such as the linear representation of the probability density function (PDF) of the distribution, quantile function, ordinary and incomplete moments, moment generating function and distribution of the order statistic were derived. The PDF and hazard rate function were found to be capable of having various shapes, making the new distribution highly flexible. In particular, the hazard rate function can be nonincreasing, unimodal and nondecreasing. It can also have the bathtub shape among other non- monotone shapes. The maximum likelihood procedure was used to estimate the parameters of the new model. We gave two numerical examples to illustrate the usefulness and the ability of the distribution to provide better fits to a number of data sets than several distributions in existence.
\end{abstract}

Keywords: Burr III distribution; maximum likelihood procedure; moments; odd exponentiated halflogistic-G family; order statistics.

\begin{abstract}
Abstrak
Pada artikel ini akan didefinisikan dan dipelajari mengenai distribusi baru yang disebut distribusi Burr III setengah logistik tereksponen ganjil. Kami menurunkan beberapa sifat dari distribusi tersebut yaitu representasi linier dari fungsi kepadatan peluang (FKP), fungsi kuantil, momen biasa dan momen tidak lengkap, fungsi pembangkit momen dan distribusi statistik terurut. Fungsi FKP dan fungsi tingkat hazard diperoleh memiliki bermacam-macam bentuk, membuat distribusi baru ini sangat fleksibel. Secara kbusus, fungsi tingkat hazard dapat berupa fungsi taknaik, bermodus tunggal, bisa juga tidak, turun. Selain itu, fungsi ini juga dapat berbentuk, seperti bak, mandi di antara bentukbentuk. tak monoton lainnya. Prosedur kemungkinan maksimum digunakan untuk. mengestimasi parameter model yang baru. Kami memberikan dua contob numerik untuk. mengilustrasikan kegunaan dan kemampuan distribusi untuk menghasilkan kesesuaian yang lebih baik. pada sejumlah kumpulan data dibandingkan beberapa distribusi yang ada.

Kata kunci: distribusi Burr III; prosedur kemungkinan maksimum; momen; keluarga setengab logistik-G teresponen ganjil; statistic terurut.
\end{abstract}

\section{INTRODUCTION}

The Burr III (BIII) distribution, which is basically the distribution of the inverse transformation of the Burr XII random variable has found applications in actuarial science, environmental science, meteorology, reliability theory and survival analysis. The BIII distribution that depends on two parameters ( $a$ and $b$ ), where $a$ and $b$ are shape parameters, has the cumulative distribution function $(\mathrm{CDF})$ and probability density function (PDF) defined by

and

$$
G(x, a, b)=\left(1+x^{-a}\right)^{-b}, x>0, a, b>0,
$$

Submitted December 25 ${ }^{\text {th }}$ 2020, Revised March 28 ${ }^{\text {th }}$, 2021, Accepted for publication March $29^{\text {th }}, 2021$.

This is an open access article under CC-BY-SA license (https://creativecommons.org/licence/by-sa/4.0/) 


$$
g(x, a, b)=a b x^{-(a+1)}\left(1+x^{-a}\right)^{-(b+1)}, x>0, a, b>0,
$$

respectively.

Being one of the baseline distributions, there are situations the BIII distribution does not reasonably fit the data under consideration. In such situations, a generalization of the distribution can be considered. Several generalizations of the BIII distribution abound in the statistical science literature. [1] introduced the beta BIII distribution as well as the log-beta BIII regression model for analyzing censored data. The McDonald BIII distribution has been studied by [2], with emphasis on its mathematical properties and applications. A generalization of the BIII distribution called the modified BIII distribution has been introduced by [3]. In their paper, they showed categorically the relationships between the modified BIII distribution and each of the generalized inverse Weibull and loglogistic distributions. The transmuted and generalized BIII distributions were developed by [4] and [5], respectively. In another generalization of the BIII distribution, [6] introduced the odd BIII distributions. A special case of the gamma-generated family of distributions called the gamma BIII distribution was defined by [7]. Following the findings made by the authors, the hazard rate function of the distribution can be a decreasing, unimodal or decreasing-increasing-decreasing function. The log-gamma regression was also proposed by [7].

In this paper, we introduce and study a new extension of the BIII distribution called the odd exponentiated half logistic BIII (OEHLBIII) distribution, which can be sufficiently flexible to provide good fits to data from various fields. The new distribution is defined based on the odd exponentiated half logistic-G (OEHL-G) family of distributions introduced by [8].

Consider a parameter vector $\xi$ and the corresponding baseline $\operatorname{CDF} G(x, \xi)$. Let $g(x, \xi)$ be the baseline PDF. For $x \in \mathbb{R}$ and two positive shape parameters $\alpha$ and $\lambda$, the CDF of the OEHL-G family has the form

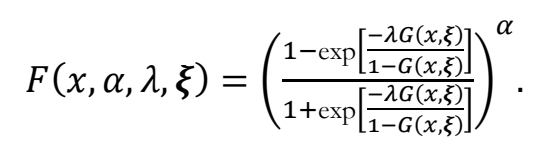

Associated with the CDF in (3) is the PDF

$$
f(x, \alpha, \lambda, \xi)=2 \alpha \lambda g(x, \xi) \frac{\exp \left[\frac{-\lambda G(x, \xi)}{1-G(x, \xi)}\right]\left[1-\exp \left[\frac{-\lambda G(x, \xi)}{1-G(x, \xi)}\right]\right]^{\alpha-1}}{[1-G(x, \xi)]^{2}\left[1+\exp \left[\frac{-\lambda G(x, \xi)}{1-G(x, \xi)}\right]\right]^{\alpha+1}} .
$$

Now, we proceed to determine the CDF and PDF of the OEHLBIII distribution. Substituting the CDF (1) into (3), the CDF of the OEHLBIII distribution is found to be

$$
F(x, \alpha, \lambda, a, b)=\left(\frac{1-\exp \left(\frac{\lambda}{1-\left(1+x^{-a}\right)^{b}}\right)}{1+\exp \left(\frac{\lambda}{1-\left(1+x^{-a}\right)^{b}}\right)}\right)^{\alpha}, \alpha, \lambda, a, b>0, x>0 .
$$

By differentiating (5) with respect to $x$, we find that the OEHLBIII distribution has the PDF

$$
f(x, \alpha, \lambda, a, b)=\frac{2 \alpha \lambda a b x^{-(a+1)}\left(1+x^{-a}\right)^{-(b+1)} \exp \left(\frac{\lambda}{1-\left(1+x^{-a}\right)^{b}}\right)\left(1-\exp \left(\frac{\lambda}{1-\left(1+x^{-a}\right)^{b}}\right)\right)^{\alpha-1}}{\left(1-\left(1+x^{-a}\right)^{-b}\right)^{2}\left(1+\exp \left(\frac{\lambda}{1-\left(1+x^{-a}\right)^{b}}\right)\right)^{\alpha+1}}
$$


In (5) and (6), the parameters $\alpha, \lambda, a$ and $b$ are positive and shape parameters, making the OEHLBIII distribution highly flexible.

Next, we examine plots of the PDF and hazard rate function (HRF) of the distribution. The OEHLBIII PDF plots for some selected values of its parameters are presented in Figure 1.
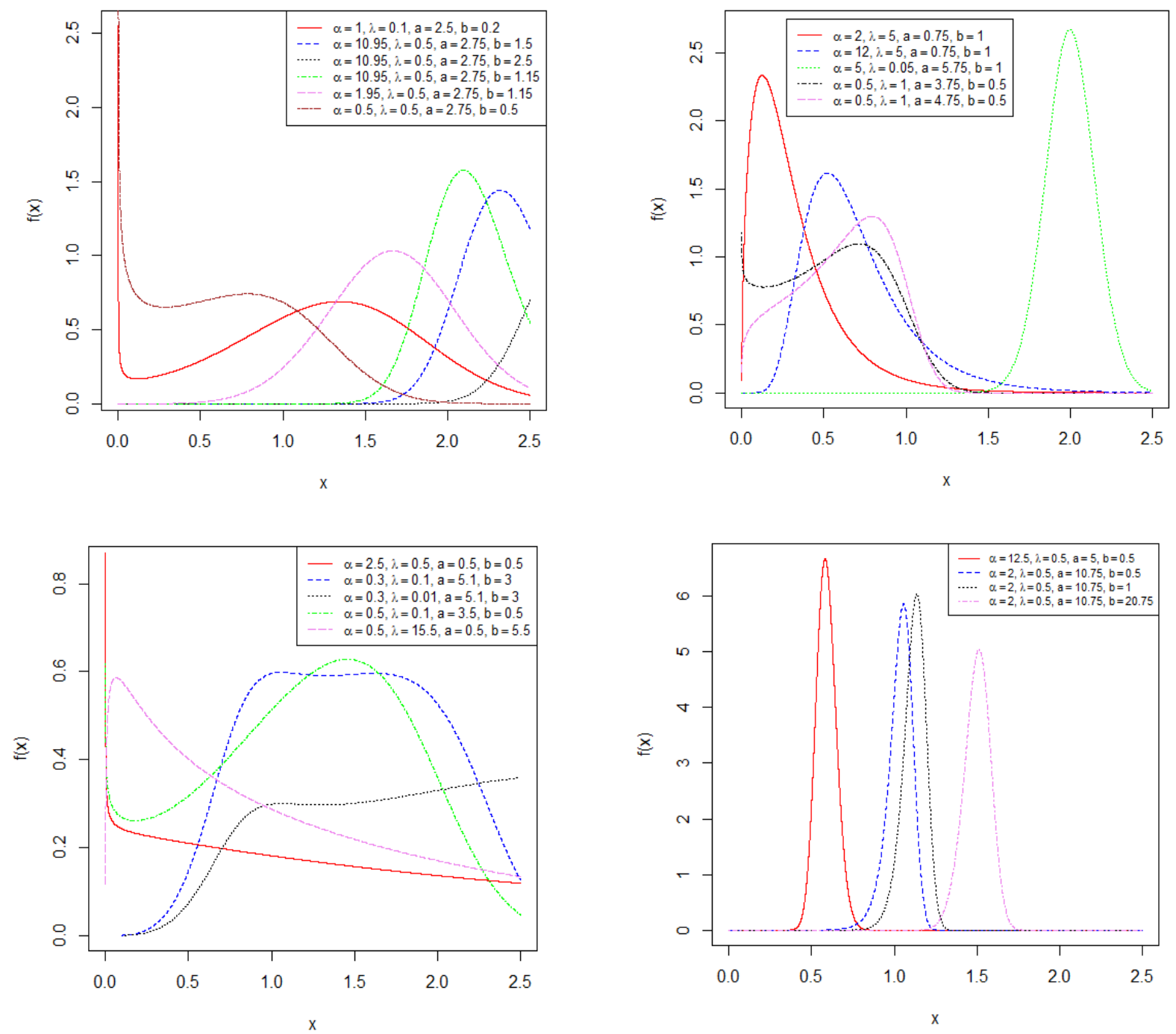

Figure 1. PDF of the OEHLBIII distribution for some selected parameter values.

The plots reveal that the PDF of the distribution can be left-skewed, right-skewed, nondecreasing, nonincreasing or unimodal. Given the OEHLBIII distribution, the hazard rate function (HRF) is defined to be

$$
h(x)=\frac{f(x, \alpha, \lambda, a, b)}{1-F(x, \alpha, \lambda, a, b)}=\frac{f(x)}{1-F(x)} .
$$

For the various shapes of the HRF, we consider Figure 2. In Figure 2, it is obvious that the HRF is capable of having any bathtub, upside down bathtub and L shapes. Additionally, the HRF can also be an increasing function or unimodal. 

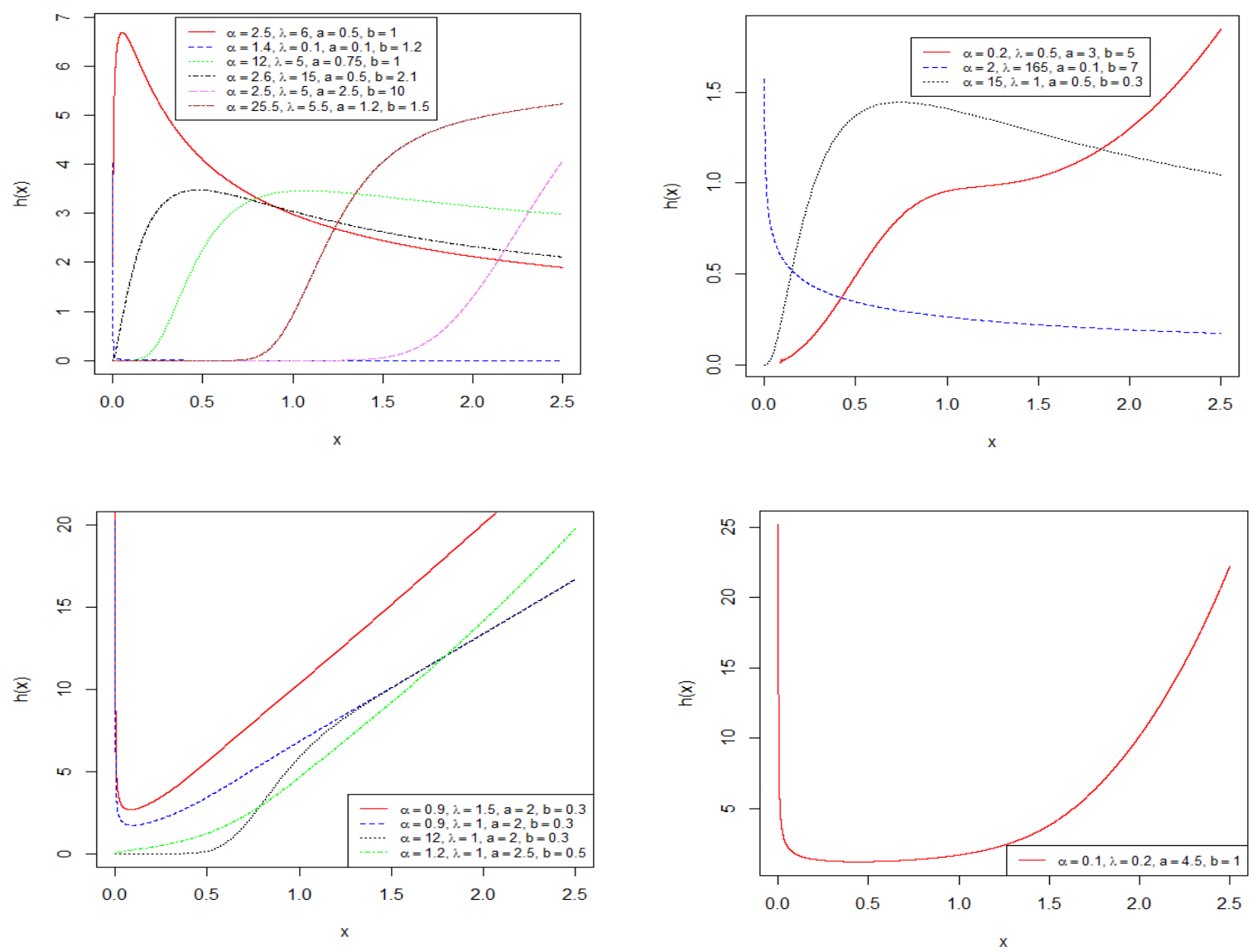

Figure 2. HRF of the OEHLBIII distribution for some selected parameter values.

\section{PROPERTIES OF THE NEW DISTRIBUTION}

In this section, we provide some mathematical properties of the new distribution.

\subsection{Linear Representation of the OEHLBIII Distribution}

The PDF (6) can be written as

$$
f(x)=\sum_{k, l=0}^{\infty} a_{k, l} h_{k+l+1}(x),
$$

such that $a_{k, 1}=2 \alpha \lambda \sum_{i, j=0}^{\infty} \frac{(-1)^{j+k+l}(\lambda(i+j+k))^{k}}{k !(k+l+1)}\left(\begin{array}{l}-\alpha-1 \\ i\end{array}\right)\left(\begin{array}{l}\alpha-1 \\ j\end{array}\right)\left(\begin{array}{l}-k-2 \\ l\end{array}\right)$ and $h_{k+l+1}(x)=(k+l+$ 1) $a b x^{-(a+1)}\left(1+x^{-a}\right)^{-b(k+l+1)-1}$ is the Burr III (BIII) density with power parameters a and $\mathrm{b}(\mathrm{k}+\mathrm{l}+1)$. With (7), it is possible to derive mathematical properties of the OEHLBIII distribution using those of the BIII distribution. Let $Z$ be a BIII random variable. If $a>r$, the r-th raw moment and incomplete moment of $Z$ are

and

$$
\mu_{r}^{\prime}=b B_{2}\left(1-\frac{r}{a}, b+\frac{r}{a}\right)
$$




$$
\varphi(t)=\int_{0}^{t} x^{r} g(x, a, b) d x=b B_{2}\left(t^{-\frac{1}{a}}, 1-\frac{r}{a}, b+\frac{r}{a}\right)
$$

respectively, where

$$
B_{2}(a, b)=\int_{0}^{\infty} z^{a-1}(z+1)^{-(a+b)} d z \text {, and } B_{2}(t, a, b)=\int_{t}^{\infty} z^{a-1}(z+1)^{-(a+b)} d z,
$$

are the beta and incomplete beta functions of the second kind.

\subsection{Quantile Function and Random Number Generation}

Suppose $\mathrm{F}(\mathrm{Q}(\mathrm{w}))$ is the CDF of the OEHLBIII distribution evaluated at $x=Q(w)$. $Q(w)$ is called the quantile function for the distribution if $F(Q(w))=w, 0<w<1$. Therefore

$$
Q(w)=\left(\left(\frac{\log _{e}\left(1-w^{\frac{1}{\alpha}}\right)-\log _{e}\left(1+w^{\frac{1}{\alpha}}\right)-\lambda}{\log _{e}\left(1-w^{\frac{1}{\alpha}}\right)-\log _{e}\left(1+w^{\frac{1}{\alpha}}\right)}\right)^{\frac{1}{b}}-1\right)^{-\frac{1}{a}} .
$$

Let $U$ denote a standard uniformly distributed variable. That is $U \sim U(0,1)$. By applying the inverse $\mathrm{CDF}$ technique, it can be shown that the variable

$$
X=\left(\left(\frac{\log _{e}\left(1-U^{\frac{1}{\alpha}}\right)-\log _{e}\left(1+U^{\frac{1}{\alpha}}\right)-\lambda}{\log _{e}\left(1-U^{\frac{1}{\alpha}}\right)-\log _{e}\left(1+U^{\frac{1}{\alpha}}\right)}\right)^{\frac{1}{b}}-1\right)^{-\frac{1}{a}} .
$$

has the OEHLBIII distribution with parameters $\alpha, \lambda, a$ and $b$. In this regard, we write $X \sim O E H L B I I I(\alpha, \lambda, a, b)$. Hence, for fixed values of $\alpha, \lambda, a$ and $b$, the OEHLBIII distributed data can be simulated using the formula

$$
x=\left(\left(\frac{\log _{e}\left(1-u^{\frac{1}{\alpha}}\right)-\log _{e}\left(1+u^{\frac{1}{\alpha}}\right)-\lambda}{\log _{e}\left(1-u^{\frac{1}{\alpha}}\right)-\log _{e}\left(1+u^{\frac{1}{\alpha}}\right)}\right)^{\frac{1}{b}}-1\right)^{-\frac{1}{a}},
$$

where $0<u<1$ and $u$ is a random observation on $U$.

\subsection{Raw and Incomplete Moments}

For $a>r$ and with (8), the $r$-th raw moment of the OEHLBIII variable $X$ is

$$
\mu_{r}^{\prime}=b \sum_{k, l=0}^{\infty} a_{k, l}(k+l+1) \beta_{2}\left(1-\frac{r}{a}, b(k+l+1)+\frac{r}{a}\right) .
$$

The mean of $X$ corresponds to $r=1$. The mean, variance, skewness and kurtosis of the distribution for various values of the parameters are shown in Table 1 . Table 1 indicates that if $\alpha, a$ and $b$ are fixed, the mean and variance of the OEHLBIII distribution decrease as $\lambda$ increases. Additionally, the kurtosis is an increasing function of $\lambda$. 
Table 1. Mean, Variance, Skewness and Kurtosis for Some Parameter Values of OEHLBIII Distribution

\begin{tabular}{rrrrrrrr}
\hline $\boldsymbol{\alpha}$ & $\boldsymbol{\lambda}$ & $\boldsymbol{a}$ & $\boldsymbol{b}$ & Mean & Variance & Skewness & Kurtosis \\
\hline 0.5 & 0.5 & 0.5 & 0.5 & 1.4952 & 16.3649 & 7.3560 & 106.3337 \\
\hline 0.5 & 1.5 & 0.5 & 0.5 & 0.1213 & 0.1407 & 8.5831 & 144.7057 \\
\hline 0.5 & 2.5 & 0.5 & 0.5 & 0.0339 & 0.0133 & 9.7117 & 186.2283 \\
\hline 0.5 & 3.5 & 0.5 & 0.5 & 0.0140 & 0.0026 & 10.4446 & 224.0405 \\
\hline 0.5 & 5.0 & 0.5 & 0.5 & 0.0052 & 0.0005 & 12.1493 & 297.4591 \\
\hline 0.5 & 0.5 & 1.5 & 2.0 & 2.1803 & 2.7013 & 1.0580 & 4.1035 \\
\hline 0.5 & 1.5 & 1.5 & 2.0 & 1.1628 & 0.6470 & 0.9569 & 3.8894 \\
\hline 0.5 & 2.5 & 1.5 & 2.0 & 0.8879 & 0.3432 & 0.8784 & 3.7117 \\
\hline 0.5 & 3.5 & 1.5 & 2.0 & 0.7496 & 0.2296 & 0.8187 & 3.5722 \\
\hline 0.5 & 5.0 & 1.5 & 2.0 & 0.6309 & 0.1524 & 0.7499 & 3.4090 \\
\hline 0.5 & 0.5 & 1.5 & 0.5 & 0.6699 & 0.4270 & 1.2053 & 2.7289 \\
\hline 1.5 & 0.5 & 1.5 & 0.5 & 1.2416 & 0.4471 & 0.6626 & 3.5325 \\
\hline 2.5 & 0.5 & 1.5 & 0.5 & 1.5187 & 0.4067 & 0.6161 & 3.6295 \\
\hline 3.5 & 0.5 & 1.5 & 0.5 & 1.6947 & 0.3776 & 0.6253 & 3.7253 \\
\hline 5.0 & 0.5 & 1.5 & 0.5 & 1.8704 & 0.3625 & 0.4615 & 4.2683 \\
\hline 1.5 & 2.0 & 0.5 & 2.5 & 10.1153 & 161.8494 & 3.8169 & 31.5417 \\
\hline 1.5 & 2.0 & 1.5 & 2.5 & 1.8939 & 0.5400 & 0.6395 & 3.6150 \\
\hline 1.5 & 2.0 & 2.5 & 2.5 & 1.4401 & 0.1164 & 0.1752 & 2.9700 \\
\hline 1.5 & 2.0 & 3.5 & 2.5 & 1.2900 & 0.0487 & -0.0054 & 2.6650 \\
\hline 1.5 & 2.0 & 5.0 & 2.5 & 1.1913 & 0.0209 & -0.2309 & 3.4431 \\
\hline 1.5 & 2.5 & 2.0 & 0.5 & 0.4167 & 0.0444 & 0.4697 & 3.0577 \\
\hline 1.5 & 2.5 & 2.0 & 1.5 & 1.0504 & 0.1138 & 0.3016 & 3.1239 \\
\hline 1.5 & 2.5 & 2.0 & 2.5 & 1.4570 & 0.1732 & 0.3340 & 3.1591 \\
\hline 1.5 & 2.5 & 2.0 & 3.5 & 1.7769 & 0.2313 & 0.3598 & 3.1762 \\
\hline 1.5 & 2.5 & 2.0 & 5.0 & 2.1719 & 0.3185 & 0.3800 & 3.1950 \\
\hline & & & & & & &
\end{tabular}

If $\lambda, a$ and $b$ are kept constant, the mean increases as $\alpha$ increases. Holding $\alpha, \lambda$ and $b$ constant results in the decreasing values of the mean, variance, skewness and kurtosis as $a$ increases. Mean, variance and kurtosis increase as $b$ increases provided the other parameters are constant. Using (7) and (9), the $r$-th incomplete moment of the distribution is found to be

$$
\phi_{r}(t)=b \sum_{k, l=0}^{\infty} a_{k, l}(k+l+1) \beta_{2}\left(t^{-\frac{1}{a}}, 1-\frac{r}{a}, b(k+l+1)+\frac{r}{a}\right) .
$$

\subsection{Moment Generating Function}

We can express the MGF of the OEHLBIII distribution as

$$
M_{X}(t)=\sum_{k, l=0}^{\infty} a_{k, l} M_{b(k+l+1)}(t),
$$

where $M_{b(k+l+1)}(t)$ is the MGF of the BIII distribution with parameters $a$ and $b(k+l+1)$. [1] have derived the MGF of a three-parameter BIII distribution with two shape parameters $\alpha$ and $\beta$ and a scale parameter $s$, leading to the formula

$$
M_{B I I I}(t)=\frac{\beta s m}{p} I^{\prime}\left(-s t, \frac{\beta m}{p}-1, \frac{m}{p},-\beta-1\right), t<0,
$$


where $\alpha=\frac{m}{p}$, such that both $\mathrm{m}$ and $\mathrm{p}$ are positive integers. Next, we consider a special case of (16) in which $\alpha=a, \beta=b$ and $s=1$ to obtain

$$
M_{b(k+l+1)}(t)=a b I^{\prime}(-t, a b-1, a,-b-1) .
$$

Therefore $M_{X}(t)=a b \sum_{k, l=0}^{\infty} a_{k, l} I^{\prime}(-t, a b-1, a,-b-1)$, where

$$
I^{\prime}(-t, a b-1, a,-b-1)=\int_{0}^{\infty} x^{a b-1}\left(1+x^{a}\right)^{-b-1} \exp (t x) d x .
$$

\subsection{Order Statistics}

Suppose we have a random sample $X_{1}, X_{2}, X_{3}, \ldots, X_{n}$ of size $\mathrm{n}$ from the OEHLBIII distribution and the corresponding order statistics $X_{(1)}, X_{(2)}, X_{(3)}, \ldots, X_{(n)}$. The pdf of the $i$-th order statistic can be written as [9]

$$
f_{i: n}(x)=\frac{n !}{(i-1) !(n-1) !} f(x) \sum_{j=0}^{n-i}(-1)^{j}\left(\begin{array}{l}
n-i \\
j
\end{array}\right) F^{i+j-1}(x)
$$

By applying Equation (20) in [8], we have

$$
\begin{aligned}
f(x) F^{i+j-1}(x)= & \sum_{s, w, k, l=0}^{\infty} \frac{2 \alpha \lambda^{k+1} a b(-1)^{s+k+l} x^{-(a+1)}\left(1+x^{-a}\right)^{-b(k+2)-1}}{k !(s+w+1)^{-k}}\left(\begin{array}{c}
\alpha(i+j)-1 \\
s
\end{array}\right) \\
& \times\left(\begin{array}{c}
-\alpha(i+j)-1 \\
w
\end{array}\right)\left(\begin{array}{c}
-k-2 \\
l
\end{array}\right) .
\end{aligned}
$$

Substituting (19) into (18) leads to

$$
f_{i: n}(x)=\sum_{k, l=0}^{\infty} b_{k, l} h_{b(k+l+1)},
$$

where $h_{b(k+l+1)}$ refers to the BIII density with parameters $a$ and $b(k+l+1)$ and

$$
b_{k, l}=\sum_{j=0}^{n-i} \sum_{s, w=0}^{\infty} \frac{2 \alpha \lambda^{k+1} a b(-1)^{j+k+l+s}}{k !(k+l+1)(s+w+1)^{-k}}\left(\begin{array}{l}
\alpha(i+j)-1 \\
\leftrightarrow \leftrightarrow s
\end{array}\right)\left(\begin{array}{l}
-\alpha(i+j)-1 \\
\leftrightarrow \leftrightarrow w
\end{array}\right)\left(\begin{array}{l}
-k-2 \\
l
\end{array}\right) .
$$

Furthermore, the $r$-th moment of the $i$-th order statistic is

$$
E\left(X_{i: n}^{r}\right)=b \sum_{k, l=0}^{\infty} b_{k, l}(k+l+1) \beta_{2}\left(1-\frac{r}{a}, b(k+l+1)+\frac{r}{a}\right) .
$$

\section{ESTIMATION}

The maximum likelihood estimation of the parameters of the OEHLBIII distribution is implemented by maximizing the associated likelihood function. For a random sample of size $\mathrm{n}$ from the OEHLBIII distribution, the log-likelihood function is

$$
\begin{aligned}
\log L= & n \log (2 \alpha \lambda a b)-(a+1) \sum_{i=1}^{n} \log x_{i}-(b+1) \sum_{i=1}^{n} \log \left(1+x_{i}^{-a}\right)+\lambda \sum_{i=1}^{n} t_{i} \\
& +(\alpha-1) \sum_{i=1}^{n} \log \left(1-\exp \left(\lambda t_{i}\right)\right)-2 \sum_{i=1}^{n} \log \left(1-\left(1+x_{i}^{-a}\right)^{-b}\right)-(\alpha+1) \times \\
& \sum_{i=1}^{n} \log \left(1+\exp \left(\lambda t_{i}\right)\right),
\end{aligned}
$$


where $t_{i}=\left(1-\left(1+x_{i}^{-a}\right)^{b}\right)^{-1}$.

The partial derivatives associated with $\log L$ are

$$
\begin{aligned}
\frac{\partial \log L}{\partial \alpha}= & \frac{n}{\alpha}+\sum_{i=1}^{n} \log \left(1-\exp \left(\lambda t_{i}\right)\right)-\sum_{i=1}^{n} \log \left(1+\exp \left(\lambda t_{i}\right)\right), \\
\frac{\partial \log L}{\partial \lambda}= & \frac{n}{\lambda}+\sum_{i=1}^{n} t_{i}-(\alpha-1) \sum_{i=1}^{n} \frac{t_{i} \exp \left(\lambda t_{i}\right)}{1-\exp \left(\lambda t_{i}\right)}-(\alpha+1) \sum_{i=1}^{n} \frac{t_{i} \exp \left(\lambda t_{i}\right)}{1+\exp \left(\lambda t_{i}\right)} \\
\frac{\partial \log L}{\partial a}= & \frac{n}{a}-\sum_{i=1}^{n} \log x_{i}+(b+1) \sum_{i=1}^{n} \frac{x_{i}^{-a} \log x_{i}}{1+x_{i}^{-a}}-\lambda b \sum_{i=1}^{n} x_{i}^{-a}\left(1+x_{i}^{-a}\right)^{b-1} t_{i}{ }^{2} \log x_{i} \\
& +\lambda b(\alpha-1) \sum_{i=1}^{n} \frac{x_{i}^{-a}\left(1+x_{i}^{-a}\right)^{b-1} t_{i}^{2} \exp \left(\lambda t_{i}\right) \log x_{i}}{1-\exp \left(\lambda t_{i}\right)} \\
& +2 b \sum_{i=1}^{n} \frac{x_{i}^{-a} \log x_{i}}{\left(1-\left(1+x_{i}^{-a}\right)^{-b}\right)\left(1+x_{i}{ }^{-a}\right)^{b+1}} \\
& +\lambda b(\alpha+1) \sum_{i=1}^{n} \frac{x_{i}^{-a}\left(1+x_{i}^{-a}\right)^{b-1} t_{i}{ }^{2} \exp \left(\lambda t_{i}\right) \log x_{i}}{1+\exp \left(\lambda t_{i}\right)}
\end{aligned}
$$

and

$$
\begin{aligned}
\frac{\partial \log L}{\partial b}= & \frac{n}{b}-\sum_{i=1}^{n} \log \left(1+x_{i}^{-a}\right)+\lambda \sum_{i=1}^{n}\left(1+x_{i}^{-a}\right)^{b} t_{i}^{2} \log \left(1+x_{i}^{-a}\right) \\
& -\lambda(\alpha-1) \sum_{i=1}^{n} \frac{\left(1+x_{i}^{-a}\right)^{b} t_{i}^{2} \exp \left(\lambda t_{i}\right) \log \left(1+x_{i}^{-a}\right)}{1-\exp \left(\lambda t_{i}\right)} \\
& -2 \sum_{i=1}^{n} \frac{\left(1+x_{i}^{-a}\right)^{-b} \log \left(1+x_{i}^{-a}\right)}{1-\left(1+x_{i}^{-a}\right)^{-b}}-\lambda(\alpha+1) \sum_{i=1}^{n} \frac{\left(1+x_{i}^{-a}\right)^{b} t_{i}{ }^{2} \exp \left(\lambda t_{i}\right) \log \left(1+x_{i}^{-a}\right)}{1+\exp \left(\lambda t_{i}\right)}
\end{aligned}
$$

Finding the maximum likelihood estimates of the respective parameters amounts to solving the equations $\frac{\partial \log L}{\partial \alpha}=0, \frac{\partial \log L}{\partial \lambda}=0, \frac{\partial \log L}{\partial a}=0$ and $\frac{\partial \log L}{\partial b}=0$ simultaneously. Since the analytical solution of the equations cannot be found, a numerical approach to solving the equations may be considered.

\section{APPLICATIONS}

In this section, we illustrate the flexibility and applicability of OEHLBIII distribution (OEHLBIIID) using two real data sets. The first data (Data 1) comprising the annual maximum daily precipitation data (in millimeters) which was reported in Busan, Korea, from 1904 to 2011 are recorded in Table 2. Data 1 have been modelled by authors such as [10] [11] [12] [13]. The second data set (Data 2) was reported by [14] and subsequently modelled by [3]. The data (fracture toughness $\mathrm{MPa} \mathrm{m}^{1 / 2}$ data from the material Alumina) are presented in Table 3. 
Table 2. Annual maximum daily precipitation data

24.8,140.9,54.1,153.5,47.9,165.5,68.5,153.1,254.7,175.3,87.6,150.6,147.9,354.7,128.5,150.4, 119.2,69.7,185.1,153.4,121.7,99.3,126.9,150.1,149.1,143,125.2,97.2,179.3,125.8,101,89.8, 54.6,283.9,94.3,165.4,48.3,69.2,147.1,114.2,159.4,114.9,58.5,76.6,20.7,107.1,244.5,126,122.2,219.9,153.2,145.3,101.9,13 5.3,103.1,74.7,174,126,144.9,226.3,96.2,149.3,122.3,164.8,188.6,273.2,61.2,84.3,130.5,96.2,155.8,194.6,92,131,137,106. 8,131.6,268.2,124.5,147.8,294.6, 101.6,103.1,247.5,140.2,153.3,91.8,79.4,149.2,168.6,127.7,332.8,261.6,122.9,273.4,178,177, $108.5,115,241,76,127.5,190,259.5,301.5$.

Table 3. Fracture toughness data

$5.5,5,4.9,6.4,5.1,5.2,5.2,5,4.7,4,4.5,4.2,4.1,4.56,5.01,4.7,3.13,3.12,2.68,2.77,2.7,2.36,4.38,5.73,4.35,6.81$, 1.91

2.66, 2.61, 1.68, 2.04, 2.08, 2.13, 3.8, 3.73, 3.71, 3.28, 3.9, 4, 3.8, 4.1, 3.9, 4.05, 4, 3.95, 4, 4.5, 4.5, 4.2, 4.55, 4.65, 4.1, 4.25

$4.3,4.5,4.7,5.15,4.3,4.5,4.9,5,5.35,5.15,5.25,5.8,5.85,5.9,5.75,6.25,6.05,5.9,3.6,4.1,4.5,5.3,4.85,5.3,5.45,5.1$,

$5.3,5.2,5.3,5.25,4.75,4.5,4.2,4,4.15,4.25,4.3,3.75,3.95,3.51,4.13,5.4,5,2.1$, 4.6, 3.2 , 2.5, 4.1, 3.5, 3.2, 3.3, 4.6, 4.3, $4.3,4.5,5.5,4.6,4.9,4.3,3,3.4,3.7,4.4,4.9,4.9,5$

For the two data, we compare the fits of OEHLBIID with those of beta Burr III distribution (BBIID) [1], Burr III distribution (BIIID), gamma Burr III distribution (GBIIID) [7], Kumaraswamy Burr III distribution (KBIIID) [15] and modified Burr III distribution (MBIIID) [3]. Notably, the PDFs associated with BBIID, GBIIID, KBIIID and MBIIID are respectively given by

$$
\begin{gathered}
f(\alpha, \lambda, a, b, s)=\frac{a b}{s\left(\frac{x}{s}\right)^{a+1} B(\alpha, \lambda)}\left[\frac{\left(\frac{x}{s}\right)^{a}}{1+\left(\frac{x}{s}\right)^{a}}\right]^{\alpha b+1}\left[1-\left(\frac{\left(\frac{x}{s}\right)^{a}}{1+\left(\frac{x}{s}\right)^{a}}\right)^{b}\right]^{\lambda-1}, \alpha, \lambda, a, b, s>0, x>0 \\
f(\alpha, a, b, s)=\frac{a b}{s\left(\frac{x}{s}\right)^{a+1} \Gamma(\alpha)}\left[\frac{\left(\frac{x}{s}\right)^{a}}{1+\left(\frac{x}{s}\right)^{a}}\right]^{b+1}\left[-\log \left(1-\left(\frac{\left(\frac{x}{s}\right)^{a}}{1+\left(\frac{x}{s}\right)^{a}}\right)^{b}\right)\right]^{\alpha-1}, \alpha, a, b, s>0, x>0 \\
f(\alpha, \lambda, a, b)=\alpha \lambda a b x^{-(a+1)}\left(1+x^{-a}\right)^{-(\alpha b+1)}\left(1-\left(1+x^{-a}\right)^{-\alpha b}\right)^{\lambda-1}, \alpha, \lambda, a, b>0, x>0 \\
f(\alpha, a, b)=a b x^{-(a+1)}\left(1+\alpha x^{-a}\right)^{-\left(\frac{b}{\alpha}+1\right)}, \alpha, a, b>0, x>0 .
\end{gathered}
$$

Notably, all the numerical results in this section are obtained using the fitdistrplus package in R. The optimization of the log-likelihood function associated with each of the six multi-parameter distributions is carried out using the default method for distributions with more than one parameter (Nelder-Mead method).

To compare the goodness of fits of the six models, we use the Akaike Information Criteria (AIC), Bayesian Information Criteria (BIC), Kolmogorov-Smirnov Statistic (KS), Cramer-von Mises (W*) and Anderson-Darling Statistic $\left(\mathrm{A}^{*}\right)$. The distribution with the best fit to each data is the distribution corresponding to minimum values of $\mathrm{AIC}, \mathrm{BIC}, \mathrm{KS}, \mathrm{W}^{*}$ and $\mathrm{A}^{*}$. 
Table 4 contains maximum likelihood estimates (MLEs) of the parameters of the distributions fitted to Data 1 and the corresponding values of $\mathrm{AIC}, \mathrm{BIC}, \mathrm{KS}, \mathrm{W}^{*}$ and $\mathrm{A}^{*}$. The results presented in Table 4 show that the OEHLBIIID has the lowest value of AIC, BIC, KS, $\mathrm{W}^{*}$ and $\mathrm{A}^{*}$. Thus, the OEHLBIIID is the best among the six models fitted to Data 1.

Table 4. MLEs of the models for Data 1, the associated standard error estimates and the values of AIC, BIC, $\mathrm{KS}, \mathrm{W}^{*}$ and $\mathrm{A}^{*}$.

\begin{tabular}{|c|c|c|c|c|c|c|c|c|}
\hline Models & Estimates & $\begin{array}{l}\text { Standard } \\
\text { Error } \\
\text { Estimates }\end{array}$ & $-\log L$ & AIC & BIC & KS & $\mathrm{W}^{*}$ & $A^{*}$ \\
\hline \multirow[t]{5}{*}{ BBIII } & $\hat{\alpha}=9.6204$ & 0.0034 & 723.5806 & 1457.161 & 1470.431 & 0.9590 & 30.8685 & 234.7095 \\
\hline & $\hat{\lambda}=0.8590$ & 0.0092 & & & & & & \\
\hline & $\hat{a}=1.2557$ & 0.4417 & & & & & & \\
\hline & $\hat{b}=0.0405$ & 0.0040 & & & & & & \\
\hline & $\hat{s}=7.8582$ & 0.0046 & & & & & & \\
\hline \multirow[t]{2}{*}{ BIII } & $\hat{a}=1.6501$ & 0.1028 & 608.5529 & 1221.106 & 1226.414 & 0.1453 & 0.8947 & 5.3741 \\
\hline & $\hat{b}=1992.9226$ & 893.2800 & & & & & & \\
\hline \multirow[t]{4}{*}{ GBIII } & $\hat{\alpha}=21.1858$ & 0.4501 & 594.8563 & 1197.713 & 1208.328 & 0.1300 & 0.5158 & 2.9587 \\
\hline & $\hat{a}=7.8053$ & 0.0230 & & & & & & \\
\hline & $\hat{b}=18.6784$ & 0.1153 & & & & & & \\
\hline & $\hat{s}=5.9333$ & 0.0175 & & & & & & \\
\hline \multirow[t]{4}{*}{ KBIII } & $\hat{\alpha}=0.8890$ & 0.0103 & 783.1645 & 1574.329 & 1584.945 & .5359 & 8.7151 & 40.2025 \\
\hline & $\hat{\lambda}=0.0332$ & 0.0032 & & & & & & \\
\hline & $\hat{a}=6.1611$ & 0.0034 & & & & & & \\
\hline & $\hat{b}=0.6665$ & 0.0110 & & & & & & \\
\hline \multirow[t]{4}{*}{ MBIII } & $\hat{\alpha}=48.0216$ & 74.6224 & 607.2952 & 1220.59 & 1228.552 & 0.1388 & 0.7964 & 4.8213 \\
\hline & $\hat{a}=1.7387$ & 0.1329 & & & & & & \\
\hline & $\hat{b}=3062.9954$ & 1766.040 & & & & & & \\
\hline & & 2 & & & & & & \\
\hline OEHL & $\hat{\alpha}=2.9189$ & 1.3915 & 580.8811 & 1169.762 & 1180.378 & 0.0905 & 0.1253 & 0.7427 \\
\hline \multirow[t]{3}{*}{ BIII } & $\hat{\lambda}=0.0041$ & 0.0006 & & & & & & \\
\hline & $\hat{a}=1.1794$ & 0.2566 & & & & & & \\
\hline & $\hat{b}=0.6322$ & 0.9002 & & & & & & \\
\hline
\end{tabular}

Figure 3 shows the histogram, estimated densities and estimated CDFs for Data 1. Based on this figure, we infer that the OEHLBIIID is suitable for Data 1.

In Table 5, we have the MLEs of the parameters of the models fitted to Data 2, the corresponding standard errors and $\mathrm{AIC}, \mathrm{BIC}, \mathrm{KS}, \mathrm{W}^{*}$ and $\mathrm{A}^{*}$ values. On the basis of lowest AIC, $\mathrm{BIC}, \mathrm{KS}, \mathrm{W}^{*}$ and $\mathrm{A}^{*}$ values, the OEHLBIID is the most suitable model among all the models fitted to the data. 

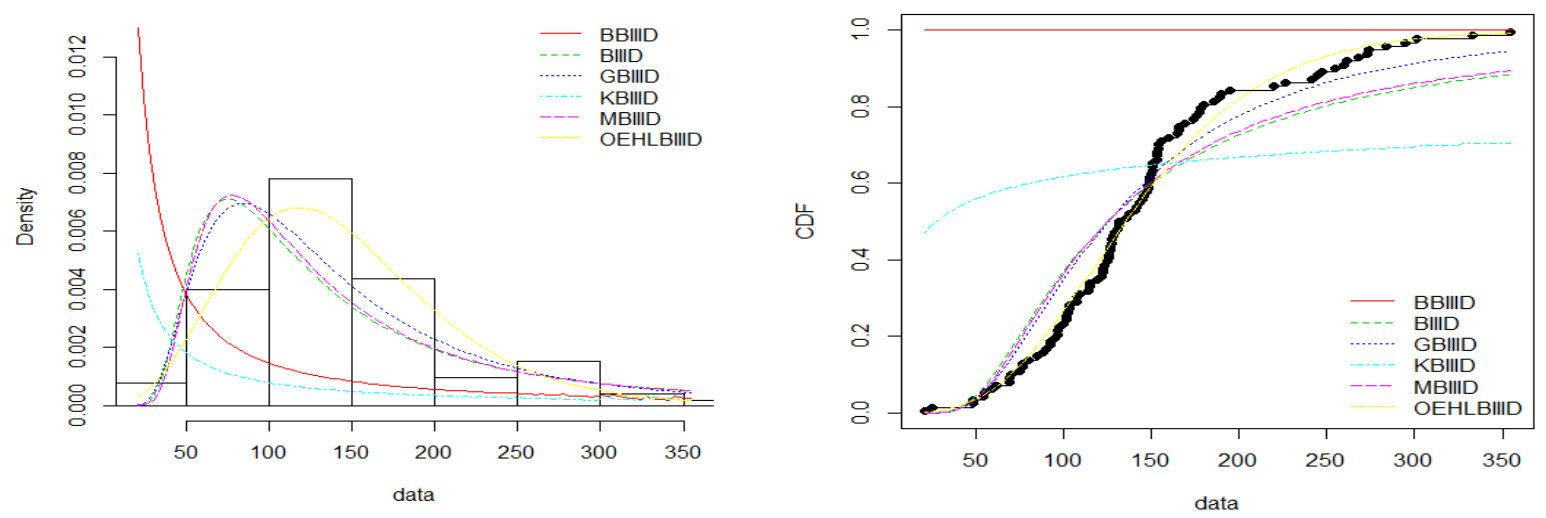

Figure 3: Estimated PDFs (left panel) and CDFs (right panel) for Data 1

Table 5. MLEs of the parameters of the models for Data 2, the associated standard error estimates and the values of $\mathrm{AIC}, \mathrm{BIC}, \mathrm{KS}, \mathrm{W}^{*}$ and $\mathrm{A}^{*}$

\begin{tabular}{|c|c|c|c|c|c|c|c|c|}
\hline Models & Estimates & $\begin{array}{l}\text { Standard } \\
\text { Error } \\
\text { Estimate }\end{array}$ & $-\log L$ & AIC & BIC & KS & $\mathrm{W}^{*}$ & $A^{*}$ \\
\hline \multirow[t]{5}{*}{ BBIII } & $\hat{\alpha}=0.0561$ & 0.1786 & 167.8023 & 345.6047 & 359.5003 & 0.9426 & 33.2240 & 228.0259 \\
\hline & $\hat{\lambda}=1.3122$ & 1.2550 & & & & & & \\
\hline & $\hat{a}=12.8125$ & 5.6904 & & & & & & \\
\hline & $\widehat{b}=5.7520$ & 18.2532 & & & & & & \\
\hline & $\hat{s}=5.2035$ & 0.2050 & & & & & & \\
\hline \multirow[t]{2}{*}{ BIII } & $\hat{a}=3.0607$ & 0.1802 & 209.7675 & 423.5350 & 429.0932 & 0.1964 & 1.4297 & 8.1098 \\
\hline & $\hat{b}=52.0622$ & 11.2352 & & & & & & \\
\hline \multirow[t]{4}{*}{ GBIII } & $\hat{\alpha}=0.2000$ & 0.0182 & 198.2675 & 404.5350 & 415.6515 & 0.7898 & 23.1824 & 120.2560 \\
\hline & $\hat{a}=5.1503$ & 0.0027 & & & & & & \\
\hline & $\hat{b}=9.3326$ & 0.0070 & & & & & & \\
\hline & $\hat{s}=3.5632$ & 0.0027 & & & & & & \\
\hline \multirow[t]{4}{*}{ KBIII } & $\hat{\alpha}=1191.205$ & 259.9667 & 173.9927 & 355.9854 & 367.1019 & 0.1114 & 0.2716 & 1.6938 \\
\hline & $\hat{\lambda}=120.4422$ & 80.3170 & & & & & & \\
\hline & $\hat{a}=1.0101$ & 0.1176 & & & & & & \\
\hline & $\hat{b}=0.0209$ & 0.0042 & & & & & & \\
\hline \multirow[t]{4}{*}{ MBIII } & $\begin{array}{l}\hat{\alpha}=1201.309 \\
4\end{array}$ & 760.4504 & 185.5963 & 377.1927 & 385.5301 & 0.1438 & 0.6534 & 3.8825 \\
\hline & $\hat{a}=5.0924$ & 0.3081 & & & & & & \\
\hline & $\widehat{b}=1433.124$ & 673.0790 & & & & & & \\
\hline & 2 & & & & & & & \\
\hline \multirow{4}{*}{$\begin{array}{l}\text { OEHL } \\
\text { BIII }\end{array}$} & $\hat{\alpha}=0.9422$ & 0.2967 & 167.6595 & 343.3191 & 354.4356 & 0.0674 & 0.0731 & 0.4411 \\
\hline & $\hat{\lambda}=0.0220$ & 0.0220 & & & & & & \\
\hline & $\hat{a}=4.3389$ & 0.8168 & & & & & & \\
\hline & $\hat{b}=12.9473$ & 20.9565 & & & & & & \\
\hline
\end{tabular}

Also, Figure 4 reveals that the OEHLBIID is a good model for the data. 

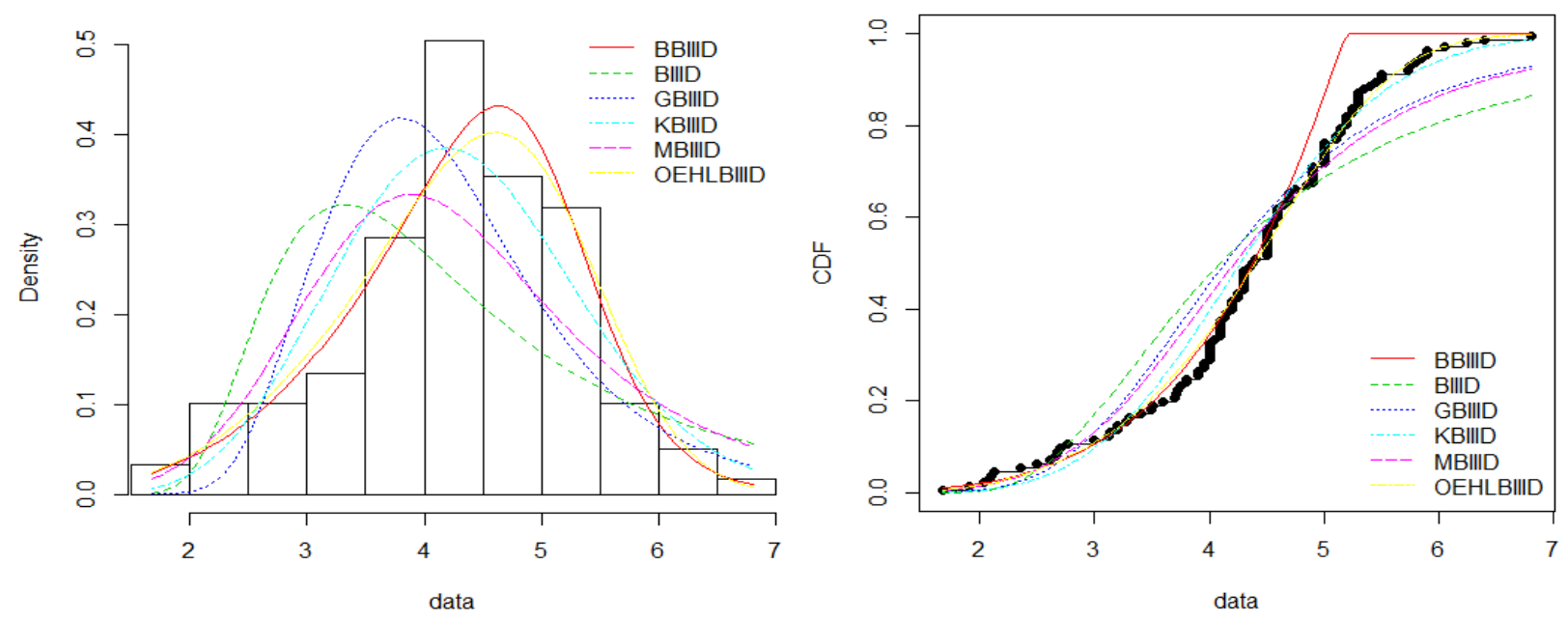

Figure 4. Estimated PDFs (left panel) and CDFs (right panel) for Data 2

\section{CONCLUSIONS}

We have extended the two-parameter Burr III distribution to obtain a new distribution called the odd exponentiated half-logistic Burr III distribution. The new distribution can be applied in reliability analysis, survival analysis, time series analysis among other fields. Properties of the distribution, namely, the linear representation of its density function, quantile function, raw and incomplete moments, moment generating function and distribution of the order statistic have been determined. The maximum likelihood method of estimating the parameters of the distribution was discussed. Comparatively speaking, the PDF and hazard rate function of the distribution introduced in this article are capable of having shapes that the PDF and hazard rate function of the baseline distribution do not have. Hence, the new model is more flexible than its corresponding baseline distribution. The numerical results obtained in this study indicate that the new distribution can be a better distribution for several data sets than many well-known continuous distributions, especially its sub model the twoparameter Burr III distribution.

Author Contributions: This work is a product of the joint effort of the authors. The first author produced the first draft of the paper and submitted it to the second author who vetted it and made suggestions.

Funding: This research received no external funding.

Acknowledgments: The authors are grateful to the three anonymous reviewers for their constructive remarks.

Conflicts of Interest: The authors declare no conflict of interest.

\section{REFERENCES}

[1] A. E. Gomes, C. Q. da-Silva, G. M. Cordeiro and E. M. M. Ortega, "The Beta Burr III Model for Lifetime Data," Brazilian Journal of Probability and Statistics, vol. 27, no. 4, pp. 502-543, 2013. 
[2] A. E. A. E. Gomes, C. Q. da-Silva and G. M. Cordeiro, "Two Extended Burr Models: Theory and Practice," Communication in Statistics-Theory and Methods, vol. 44, no. 8, pp. 1706-1734, 2015.

[3] A. Ali, S. A. Hasnain and M. Ahmad, "Modified Burr III Distribution, Properties and Applications," Pakistan Journal of Statistics, vol. 31, no. 6, pp. 697-708, 2015.

[4] I. B. Abdul-Moniem, "Transmuted Burr type III Distribution," Journal of Statistics: Advances in Theory and Applications, vol. 14, no. 1, pp. 37-47, 2015.

[5] A. Y. Al-Saiari , S. A. Mousa and L. A. Bahairith, "Marshal-Olkin Extended BIII Distribution," International Mathematical Forum, vol. 11, no. 13, pp. 631-642, 2016.

[6] F. Jamal, M. A. Nasir, M. H. Tahir and N. H. Monta, "The Odd Burr III Family of Distributions," Journal of Statistical Applications and Probability, vol. 6, no. 1, pp. 105-122, 2017.

[7] G. M. Cordeiro, A. G. Gomes, C. Q. da-Silva and E. M. M. Ortega, "A Useful Extension of the Burr III Distribution," Journal of Statistical Distributions and Applications, vol. 4, pp. 1-15, 2017.

[8] A. Z. Afify, E. Altun, M. Alizadeh, G. Ozel and G. G. Hamedani, "The Odd Exponentiated Half-Logistic-G family: Properties, Characterizations and Applications," Chilean Journal of Statistics, vol. 8, no. 2, pp. 65-71, 2017.

[9] M. A. D. Aldahlan and A. Z. Afify, "The Odd Exponentiated Half-Logistic Burr XII Distribution," Pakistan Journal of Statistics and Operation Research, vol. XIV, no. 2, pp. 305-317, 2018.

[10] B. Y. Jeong, M. S. Murshed, Y. Am Seo and J. S. Park, "A Three-Parameter Kappa Distribution with Hydrologic Application: A Generalized Gumbel Distribution," Stochastic Environmental Research and Risk. Assessment, vol. 28, pp. 2063-2074, 2014.

[11] M. Mansoor, M. H. Tahir, A. Alzaatreh and G. M. Corde, "An Extended Frechet Distribution: Properties and Applications," Journal of Data Science, vol. 14, pp. 167-188, 2016.

[12] I. E. Okorie, A. C. Akpanta, J. Ohakwe and D. C. Chikezie, "The Extended Erlang-Truncated Exponential Distribution: Properties and Application to Rainfall Data," Heliyon, vol. 3, pp. 1-24, 2016.

[13] I. E. Okorie, A. C. Akpanta, J. Ohakwe, Chikezie and D. C., "Marshall-Olkin Generalized Erlang-Truncated Exponential Distribution: Properties and Application," Cogent Mathematics, vol. 4, pp. 1-19, 2017.

[14] S. Nadarajah and K. S., "On the Alternative to the Weibull Function," Engineering Fracture Mechanics, vol. 74, pp. 577-579, 2007.

[15] S. M. Behairy, G. R. Al-Dayian and A. A. El-Helbawy, "The Kumaraswamy-Burr Type III Distribution: Properties and Estimation," British Journal of Mathematics and Computer Science, vol. 14, no. 2, pp. 1-21, 2016. 